\title{
Implementation of an Educational Programme to Facilitate Critical Thinking of Student Nurses
}

\author{
Louise Pretorius ${ }^{*}$, Hans Justus Amukugo' ${ }^{\text {, Agnes Van Dyk }}{ }^{2}$, Louis F. Small1 \\ ${ }^{1}$ School of Nursing, Faculty of Health Sciences, University of Namibia, Windhoek, Namibia \\ ${ }^{2}$ School of Nursing, International University of Management, Windhoek, Namibia \\ Email: *lpretorius@unam.nam
}

How to cite this paper: Pretorius, L., Amukugo, H.J., Van Dyk, A. and Small, L.F. (2016) Implementation of an Educational Programme to Facilitate Critical Thinking of Student Nurses. Open Access Library Journal, 3: e3063.

http://dx.doi.org/10.4236/oalib.1103063

Received: September 14, 2016

Accepted: October 22, 2016

Published: October 26, 2016

Copyright ( 2016 by authors and Open Access Library Inc.

This work is licensed under the Creative Commons Attribution International

License (CC BY 4.0).

http://creativecommons.org/licenses/by/4.0/

\begin{abstract}
The overall purpose of phase 3 was to implement the educational programme that was developed to facilitate the development of critical thinking in the student nurse. A quasi-experimental design within the quantitative approach for phase 3 was used. The purpose of a quasi-experimental design was to identify and demonstrate casual relationships, examine relationships and clarify why certain events happened. The educational programme was implemented over a period of three days, covering theoretical and practical content. The objectives for this phase were to select the two groups of final-year student nurses to fit the quasi experimental design as the experimental and control group; conduct a pre-test on both the experimental and the control group in Windhoek and Oshakati to determine their application of critical thinking skills to the management of a given case in an imaginary case scenario; implement and facilitate the educational programme over a predetermined period of three days during the second semester of training for the experimental group in Windhoek and ensure active participation by participants for the duration of the educational programme. The population for this study consisted of nursing students in their final year (fourth year) of study at the training hospitals of Windhoek and Oshakati. Both campuses are incorporated in the Faculty of Health Sciences. The full population of the fourth-year class at the Windhoek campus was selected to be part of the experimental group (47 students) and the students from Oshakati (53 students) formed the control group. The total number of students amounted to 100 students.
\end{abstract}

\section{Subject Areas}

Nursing

\section{Keywords}

Implementation, Educational Programme, Facilitate, Critical Thinking, Student Nurses 


\section{Introduction and Background}

Teaching and learning, as the most important features of this educational programme, are considered to be a dynamic process [1]. It is, however, important to note that the emphasis of this educational programme was on the learner and the learning that take place, rather than on the teaching. Teaching merely took the form of facilitation to develop critical thinking in the participants, because "without critical thinkers it is unlikely that much human progress would be made"-especially in the nursing profession [2]. Although students normally like to be "spoon fed", the facilitator aimed, during the implementation phase of the educational programme, to promote active participation so that the sessions would be meaningful and would comply with the different approaches used to design the educational programme. Spoon feeding may be convenient in the short term, but the long-term implications of passive learning are profoundly negative [3] [4].

At an international critical thinking conference, a model for teaching critical thinking was discussed. The model proposes that one of the most effective approaches for teaching critical thinking is to conduct a two-day workshop where active participation by participants is proposed. Students should be encouraged to read critically and do self-assessment during this workshop. During such a workshop, the basic concept of critical thinking should be emphasized as well as the application to the specific discipline concerned, in this study the nursing profession [5].

Just as critical thinking may be variously defined, there are different opinions about what characteristics or attribute should prevail in a critical thinker. Many authors have written on what a critical thinker should "look like", actually referring to what characteristics one would see in someone who thinks critically. But, what would one like to see in a nurse rendering nursing care to her patients/clients with critical thinking skills and a critical spirit?

A number of characteristics and attributes of critical thinkers were mentioned in the previous discussions. What is evident in the literature is that authors and researchers agree on some common characteristics that are typical of critical thinkers. These characteristics are diligence, flexibility, fair-mindedness, honesty about personal biases and prudence in judgments. A critical thinker furthermore tends to think in an orderly, focused and persistent manner, and be inquisitive and open-minded as well as well-informed although humble, creative and flexible [5] [6] [7] [8] [9].

However, for the purpose of this study the researcher would like to include the traits of mind and criteria that were described by [10] and [11]. The authors referred to the affective dispositions, traits of mind and passions that are included in higher-order thinking. The affective dimensions as included by [11] include independent thinking, fair-mindedness and insight into egocentricity and socio centricity. The development of intellectual humility and intellectual perseverance were also mentioned. According to the authors, without intellectual perseverance one could not solve the complicated multifaceted problems which are prominent in society and the profession per se. To address complicated and problematic situations, intellectual courage and fair-mindedness 
would also be essential. [10] furthermore refers to the development of intellectual good faith and integrity, confidence in reason and the exploring of thoughts. The development of intellectual curiosity was also included. Without confidence in reason one could not "adequately address those complex and frequently ambiguous real-life problems" that require reasonable decisions [11].

Critical thinkers never settle any matter without questioning. They look for alternatives while they are examining the total situation, trying to be informed and seeking for as much precision as the subject permits. While doing all that they remain sensitive to the feelings, level of knowledge and degree of sophistication of others [12]. The characteristics described are the ideal, and it is essential to realize that no critical thinker has them all and that characteristics of even the best thinkers vary. What really matters, however, is that these characteristics remain the focus of nursing education and become the pattern for critical thinking [11].

[11] described intellectual standards that are implicit in the assessment of higher order thinking. These standards include whether the evaluation were done in a relevant and consistent way, whether attention were given to accuracy and fairness and if completeness and precision was evident compared to the topic of assessment. To comply with these intellectual standards, the researcher in the compilation of the scoring rubric for the pretest and posttest, strove to be as accurate and precise as possible to secure a fair and complete scoring of the responses of the participants

\section{Aim of the Study}

The overall purpose of phase 3 was to implement the educational programme that was developed to facilitate the development of critical thinking in the student nurse.

\section{Objective}

The objectives for this phase were to

- select the two groups of final-year student nurses to fit the quasi experimental design as the experimental and control group;

- conduct a pre-test on both the experimental and the control group in Windhoek and Oshakati to determine their application of critical thinking skills to the management of a given case in an imaginary case scenario;

- implement and facilitate the educational programme over a predetermined period of three days during the second semester of training for the experimental group in Windhoek;

- ensure active participation by participants for the duration of the educational programme.

\section{Methodology}

\subsection{Design}

The researcher utilized a quasi-experimental design within the quantitative approach for phase 3. The purpose of a quasi-experimental design is to identify and demonstrate 
casual relationships, examine relationships and clarify why certain events happened. The design also explains the causal relationship between the intervention, the behaviours and related conditions targeted for change [13] [14] [15].

Quasi-experiments, like true experiments, are characterized by manipulation of an independent variable called an intervention. In this study the intervention was the implementation of the educational programme. However, quasi-experimental designs lack the randomization to treatment groups which characterizes true experiments [15] [16] [17] [18]. The strength of the quasi-experiment is that it may be practical when it is not feasible to conduct a true experiment. That was the case for this study where the researcher utilized the quasi-experimental design because randomization was not possible. A pre-test post-test control group design was implemented [18] [19].

The quasi-experimental design appeared to be the most suitable design for this study because students from two different campuses were involved and logistically randomization as for the true experiment was not possible. It would have been extremely difficult to separate two groups of students in one class on a specific campus, expecting one group to follow the educational programme and one group to be excluded from the programme and then ensure that they did not influence each other when it came to the post-test. It turned out to be more practical and feasible to involve a whole class in the educational programme since it would be difficult to keep the participants from their colleagues for the duration of the educational programme.

The researcher therefore decided to use the fourth-year nursing students from the Windhoek campus as the experimental group and participants in the educational programme, and the fourth-year nursing students from the Oshakati campus as the control group. Both groups were pre-tested and post-tested.

At this point it is worth commenting that both groups of students, although on two campuses, were following the same comprehensive nursing curriculum and have completed the same course content, as was indicated in the inclusion criteria of the design.

The quasi-experimental design is explained in Table 1.

\subsection{Population}

The population for this study consisted of nursing students in their final year (fourth year) of study at the training hospitals of Windhoek and Oshakati. Both campuses are incorporated in the Faculty of Health Sciences. The full population of the fourth-year class at the Windhoek campus was selected to be part of the experimental group (47

Table 1. Quasi-experimental design.

\begin{tabular}{|c|c|c|c|}
\hline Group & Pre-test & Intervention & Post-test \\
\hline $\begin{array}{l}\text { Experimental } \\
\text { (Windhoek: } 47 \text { students) }\end{array}$ & $\begin{array}{l}\text { - } 47 \text { students From Windhoek } \\
\text { were pre-tested }\end{array}$ & $\begin{array}{l}\text { - Intervention were only give to } 47 \text { students } \\
\text { From Windhoek were pre-tested }\end{array}$ & $\begin{array}{l}\text { - } 47 \text { students From Windhoek were } \\
\text { pre-tested }\end{array}$ \\
\hline $\begin{array}{l}\text { Control } \\
\text { (Oshakati: } 53 \text { students) }\end{array}$ & - 53 students were pre-tested & - No intervention given & - 53 students were post-tested \\
\hline
\end{tabular}

[17], [18]. 
students) and the students from Oshakati (53 students) formed the control group. The total number of students amounted to 100 students.

No sample was drawn. The whole population of 100 students (from two campuses) had the possibility of being part of the research study. This number excluded the 10 students who had participated in the pilot testing of the data collection instrument.

The inclusion criteria set for this phase corresponds with the criteria that were set for phase 1 (needs assessment). Both the groups met the following inclusion criteria: The students had completed the synthesis block of IMCI (Integrated Management of Childhood Illnesses). A period of five (5) weeks of rural community placement had been completed. During this time students had the opportunity to deal with different adult and paediatric patient cases while engaging in nursing practice.

An instrument was compiled for the pre-test at the start of the implementation phase of the educational programme. An imagined case scenario on a common paediatric case was developed for participants to analyse. The case scenario contained a relevant condition compared to the disease profile in Namibia and the condition had been included in their theoretical and clinical instruction. The format of the case scenario focused on a paediatric disorder which was covered in the theoretical as well as the clinical curriculum and education of the group of students concerned. The participants were expected to answer some relevant questions pertaining to the case scenario, to enable the researcher to determine the level of understanding and integration of critical thinking skills. The case scenario was realistic and no unreasonable expectations or far-fetched questions were asked. The questions were open ended and participants had to write their own interpretation of the question. The researcher formulated open questions in such a manner that the students were permitted creativity and initiative in their answers and the researcher was able to determine the application of the six critical thinking concepts.

For the reliability and validity, the data collection as described was carried out through a case scenario on which participants had to answer specific questions. These questions were assessed according to a memorandum and scoring rubric that was compiled by the researcher. In order to establish validity and reliability for the phase, the instrument was tested [15].

Validity refers to the soundness of the findings of the study. For an instrument to be valid it should be compiled for a specific purpose in order to measure what it is supposed to measure [15] [19]. The instrument (case scenario) that was used for the data collection in phase 3 was similar to the scenario that was developed for phase 1 with the difference that the scenario for phase 3 was more focused and specific and stemmed from the conceptual framework that was developed after the data analysis of phase 1 . Face validity (also known as content-related validity) was ensured [13] seeing that it concerned a paediatric case which was familiar to the senior nursing students. The case scenario contained no strange questions and it was envisaged that a fourth-year nursing student at that stage of his/her studies should be able to answer the questions with ease. Construct validity was also ensured by asking applicable questions in line with the 
overall purpose of the educational programme.

Reliability of the instrument in this phase refers to the accuracy, consistency and equivalence of information obtained and was established by inter-rater reliability. Equivalence or inter-rater reliability was ascertained by involving an independent rater who could assign values to the answers to the questions, independently from the researcher [13] [15]. The students' answers were analyzed by both the researcher and an independent evaluator to confirm consistency in interpretation and to detect any form of discrepancy. Moreover, student answers were rated twice to determine consistency in the rating of the researcher.

Inter-rater reliability could be determined and established by pilot testing the instrument before the researcher embarked on the pre-test at the start of the educational programme. Pilot testing of the instrument is done as part of the preparations for a major study, to exclude any misconceptions or other flaws [Ten (10)] fourth-year students participated in the pilot test of the instrument, to detect any problems regarding the questions set. The questions were then analyzed according to a scoring rubric which was compiled by the researcher to ensure consistency in marking. During analysis of the answers to the pilot test there were a few points of detail to be added to the scoring rubric to exclude misinterpretations and to refine it to perfection. This was also done to determine whether the scoring rubric was reliable for use in the analysis of the pre-test and post-test. The value of pilot testing lies in using the instrument exactly as it is going to be used in the study [13] [16] [20].

The inter-rater reliability of the scoring of the case scenario was determined by means of a Cohen's Kappa analysis. Cohen's Kappa is used in the case of two independent raters. Raters' choices are reflected in a square table where counts in diagonal cells reflect inter-rater agreement [21] [22]. An inter-rater reliability kappa coefficient of 0.82 was scored, which is considered outstanding in terms of reliability. Once the researcher was satisfied with the establishment of validity and reliability for the compilation of the instrument and scoring rubric, data collection for phase 3 could commence.

Data collection for phase 3 was carried out by means of a pre-test that included the simultaneous testing of both the students on the Windhoek campus and the students on the Oshakati campus. The rationale for the pre-test was to build a database with which the post-test could be compared in phase 4 to indicate whether the educational programme made any difference in the application of the participants' critical thinking skills, and thereby determine the success of the programme. A total number of 100 students participated in the prettest [47 in Windhoek; 53 in Oshakati]. The 10 students who participated in the pilot testing of the instrument were excluded from the pre-test. After the pre-test had been conducted and all instruments collected, data analysis followed.

Data collection for phase 3 was carried out by means of a pretest that included the simultaneous testing of both the students on the Windhoek campus and the students on the Oshakati campus. The rationale for the pretest was to build a database with which the posttest could be compared in phase 4 to indicate whether the educational 
programme made any difference in the application of the participants' critical thinking skills, and thereby determine the success of the programme. A total number of 100 students participated in the pretest [47 in Windhoek; 53 in Oshakati]. The 10 students who participated in the pilot testing of the instrument were excluded from the pretest. After the pretest had been conducted and all instruments collected, data analysis followed.

For Internal validity and reliability was done by utilizing a quasi-experimental design the researcher was responsible for establishing and maintaining internal validity in the quasi-experimental design by ruling out factors that may have been a threat to the observed outcome, thereby determining whether the outcome of the post-test was the result of the intervention [15] [23]. The threats to internal validity for this quasi-experimental design were identified and addressed as indicated in Table 2.

The researcher is therefore confident that the internal validity of the quasi-experiment was not compromised and that the change that was evident in the scores was not by chance but because of the educational programme that was offered.

After the pre-test had been distributed to the students the educational programme was offered, over a period of three days, to the students in Windhoek. The students from Oshakati continued with normal classes.

\subsection{Ethical Consideration}

The principles of beneficence and non-maleficence were adhered to because the researcher strove to minimize harm and/or discomfort and maximize benefit to the participants in the research study. The principle of self-determination was adhered to because participants had the right to decide voluntarily whether to participate in the study [15]. Prior to conducting the research, the researcher entered into an agreement with participants to clarify the nature of the research and the responsibility of each participant. This served to establish voluntary, fully informed participation of the student nurses in the completion of the questionnaire on the case scenario as well as for participation in the study. The researcher refrained from any form of coercion. Participants were protected from exploitation and they were assured that any information provided by them would not be used against them. Anonymity was ensured because only numbers appeared on the completed case scenario answers; information obtained from respondents were not identified in terms of the identity of the respondent and thereby confidentiality was ensured. The privacy of the research participants was therefore protected.

Participation in the educational programme was voluntary. The participants were free to withdraw from the educational programme at any time without incurring any penalty. Utilization of the data was discussed with the participants, prior to conducting phase 3, by filling them in on the overall aim of the study. Participants in the study enjoyed benefits and freedom from harm. Full disclosure applied to participants entering phase 3 of the study. The participants were guaranteed anonymity and confidentiality in the pre-test for phase 3. Institutional approval for the study was obtained from the 
Table 2. Management of threats to internal validity of quasi-experimental design.

\begin{tabular}{ll}
\hline \multicolumn{1}{c}{ Threat } & \multicolumn{1}{c}{ Description } \\
\hline History & $\begin{array}{l}\text { Occurrence of events concurrent with the } \\
\text { independent variable that could } \\
\text { influence/affect the outcome/dependent } \\
\text { variable. }\end{array}$ \\
Selection \\
bias/threat
\end{tabular}

Maturation

Instrumentation

Statistical regression
Improvements between testing sessions may be the result of routine changes that occur with time. This threat arises from processes occurring as a result of time rather than the independent variable.

Differences may be found because the data collection process has somehow changed. Effects may be due to changes in measurements between the pre-test and post-test rather than a result of the treatment.

Groups selected on the basis of extreme scores tend to shift toward the mean of the original group when retested. a) No extraneous effects that could have changed the ability of the control group to answer the questions of the case scenario took place.

b) Both groups were equally compiled.

c) No other courses on the subject of critical thinking were offered to the participants before or during the time they were involved in the study. They came directly from rural placement (nursing practice in communities) five weeks prior to the implementation of the educational programme.

d) The reminder that was given to the participants kept them in suspense about the content of the educational programme. It only indicated the venue, time and dress code necessary for attending the educational programme.

a) The inclusion criteria for both the experimental and the control group were the same.

b) Participation in the study was voluntary and with written consent.

c) The researcher refrained from interfering in the active participation of the participants but merely facilitated the educational programme.

d) The inclusion criteria encompassed what the participants had done in their general curriculum at the stage of the programme presentation. Both campuses have participants from different regions, and participants were all in the second semester of their fourth year at the same Department of Nursing, although at different campuses.

e) Participants were all at the same level of their education and had done the same curriculum content at the stage of the programme.

f) No interference took place at the completion of case scenario questions by the control group.

g) By setting criteria for inclusion in the educational programme, similarity between groups had been secured as far as possible.

h) Statistical analyses were done to compare groups in order to determine whether the groups were equal in compilation and academic standing before they embarked on the pre-test.

a) Participants were at the same developmental stages in their academic achievements since the year of study and other requirements for the completion of their fourth year were similar.

b) The post-test was written directly after the educational programme had been completed to limit any external input or influences when the participant went back to practice or lectures.

c) The post-test for the experimental and control group was written at the same time.

a) No changes appeared in the data collection process.

b) The pre-test and post-test that were handed to participants in both the experimental and control groups were the same.

c) Case scenarios were distributed and collected by the researcher and a research assistant, who had very clear instructions on what to do.

d) No changes were made after the reliability of the instrument had been determined.

Participants were not drawn from extreme sectors of the population. 


\section{Continued}

Experimental

mortality

Pretesting

Instability

Social-

psychological

threats

Expectancy effects
Differences subsequent testing sessions may occur because the composition of the group has changed.

The experience of taking the pre-test may sensitize subjects towards the post-test.

Chance fluctuations in scores arising from unreliability may cause changes in performance during various tests.

Dynamics of the experimental situation may set up alternative treatments that may account for differences.

Outcomes may occur because experimenter or subjects expected those outcomes. a) Care was taken by the researcher/facilitator that no participant should leave the educational programme without a valid reason.

b) If a participant had to leave the room/venue the researcher made sure that it was not because of the educational programme.

c) The researcher tried to have the full complement of participants until the end of the educational programme.

a) Both groups received the same pre-test at the same time, although at different campuses.

b) No boredom as stated by Vockell and Asher

(1995, p. 243) was observed.

An independent rater was used to secure inter-rater reliability of the scoring rubric of the case scenario questions before the rubric was finalized and utilized for scoring answers to the case scenario. Cohen Kappa's coefficient was determined to indicate inter-rater reliability.

a) Groups selected for the experimental and control groups were similar in compilation and characteristics.

b) Normal lectures went on for the control group while the experimental group underwent the educational programme.

c) Participants did not give any indication that a sense of unfairness existed among them because they were not chosen to be the experimental group.

a) The researcher did not have any expectation for the educational programme.

b) The researcher did not verbalize any expectations towards participants.

c) Case scenario given to students was in line with their academic standing since they were in their 4 th year of study.

d) The answers to the pre-test and post-test were a true reflection of their internal processes.

e) The outcome of the educational programme was therefore not distorted because of researcher expectations.

f) The researcher tried to refrain from unwittingly influencing the participants towards the desired outcome.

[13] [16] [25].

University of Namibia before phase 1 was conducted. To comply with the ethical obligation of the researcher towards the control group, study material was made available to them in the form of a self-instructional guide with clear guidelines.

\section{Process of Implementation of an Educational Programme}

\subsection{Schedule}

Implementation of the educational programme was conducted according to a specific schedule which provided for different activities to take place over three days. Participation in the educational programme was voluntary and written consent was obtained by each participant before she/he embarked on the pre-test. The participants received a programme schedule and a handout consisting of course material after the pre-test had been written. A schematic illustration of the implementation of the educational pro- 
gramme is given in Figure 1.

To put the participants at ease before commencing the educational programme, a "getting to know each other" session was conducted by the researcher in the capacity of facilitator. Thereafter participants continued with the set schedule as indicated in the programme material.

\subsection{Dynamics of Teaching during the Implementation of the Educational Programme}

The implementation of the educational programme entailed the utilization of specific teaching strategies and supportive activities that could enhance the facilitation of critical thinking by the participants. To achieve specific outcomes during the implementation of the educational programme, learning activities and conditions should be arranged to ensure that learning takes place. Learning has only taken place if it is evident

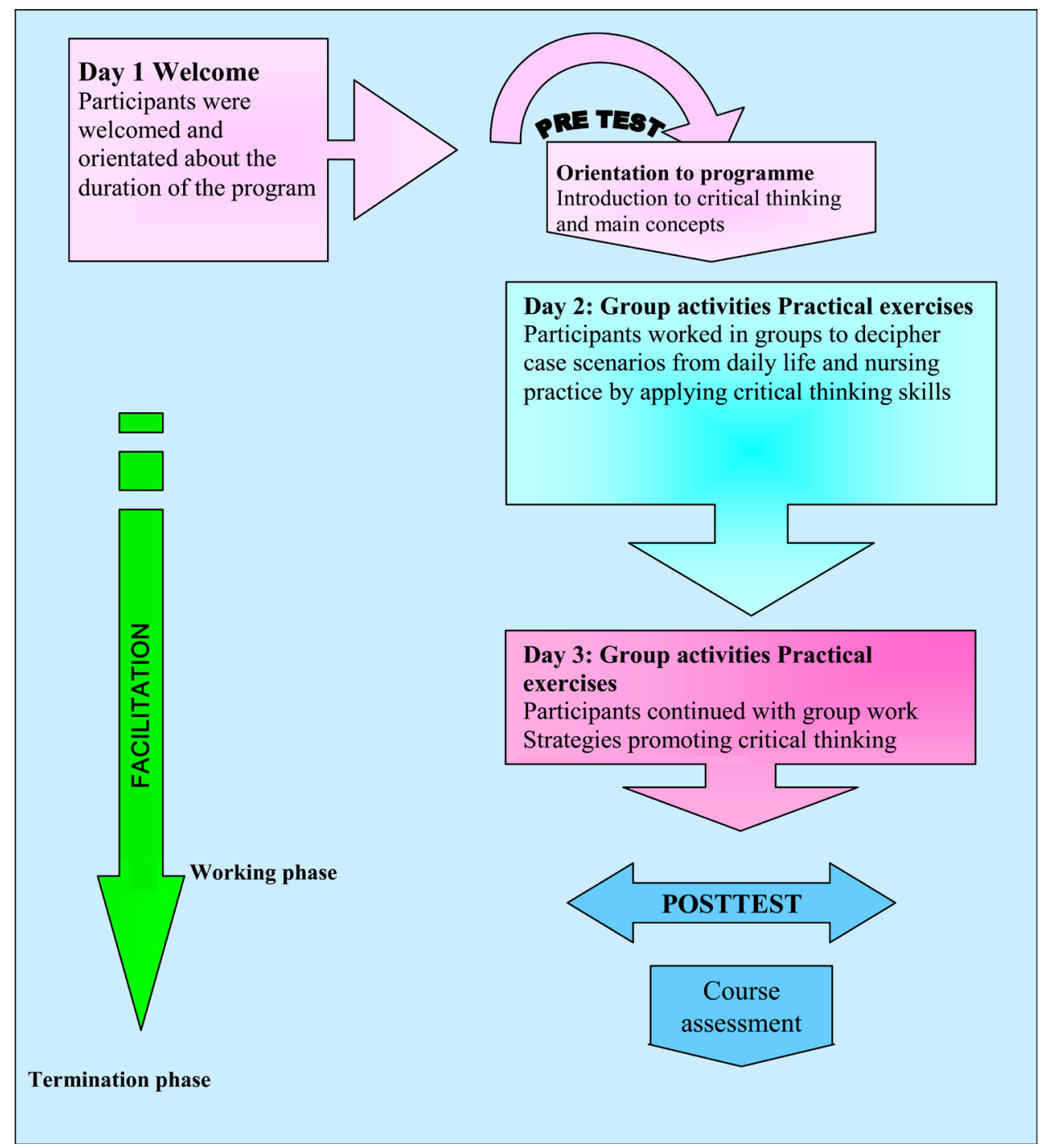

Figure 1. Process of implementation of an educational programme to facilitate the development of critical thinking in student nurses. 
in behavioural change after the intervention. To ensure that learning has taken place, learning activities should be purposefully planned to contribute to the achievement of major objectives of the educational programme [1] [24].

To achieve the objectives of this educational programme, active participation was required from the participants. Participation is described as the interchange of ideas, attempts at problem solving and active engagement of learners with each other and with the materials of instruction. Active involvement tends to increase content retention during the implementation of such a programme [1] [25] [26].

This educational programme was therefore aimed at the participants' (student nurses') behaviour in order to establish a positive change regarding utilization of critical thinking in nursing practice. Instructional activities during the educational programme included challenging the participants to think, providing mental and emotional tools to help them resolve dilemmas encountered, while the facilitator closely observed, assessed and counselled students where necessary [27] [28].

The dynamics that were employed during the facilitation of the educational programme were the following:

\section{Facilitation}

As elaborated above, the focus of the implementation of the educational programme was on active participation and dual interaction. However, the role of the researcher as facilitator in this exercise was of the utmost importance and cannot be ignored. Facilitation was an important activity throughout the implementation of the educational programme.

Facilitation is considered an essential component of learning through practice and has drawn the emphasis away from didactism [29]. It is that interactive, goal-oriented dynamic process, conducted by a facilitator, in which participants work together in an atmosphere of mutual respect, trust and comfort in order to learn by reflecting critically within an environment conducive to such thinking, while "helping each other". It has become almost synonymous with training and has become almost as challenging to both the facilitator and the group members [30] [31] [32].

The role of the facilitator during the implementation of the educational programme is to keep students on track and help them to focus on their tasks during different phases of content presentation. It is, however, of paramount importance that the balance be maintained and the exploration during this exercise for the students does not become superficial [32]. A facilitator is a "catalyst that takes a person from being a passive learner and transforms him or her into a person possessed of the power to take control of change" [33]. This transformation through promotion and development should, however, be done with empathy, respect and motivation. Motivation concerns the direction of energy with the intention of mobilizing others to act, in this case to think critically within a problem situation [31] [34].

During the presentation of the educational programme, the facilitator has to plan the strategies she/he will employ to achieve the main aim of the educational programme with great care. The role of the instructor (facilitator) is furthermore to provide a clear 
linkage between what is important (objectives), what will be learned (outcomes) and how it will be learned (teaching). The facilitator should also have the knowledge, insight and understanding of the concept concerned to facilitate a group of participants into, in this case, critical thinking. This description applied perfectly to the facilitator of this educational programme in view of the fact the participation by the participants had to be active in order to acquire the necessary critical thinking skills [30] [35] [36].

A facilitator assists learners not to focus on the "right" answer, but to think through situations where any answer is in doubt [2]. The facilitator further assesses their thinking for soundness and identifies areas for improvement during each activity. It is, however, necessary to emphasize that the facilitator will not become the learners' equal, as is believed by some educators. The role of the facilitator is to stimulate, organize, integrate and bring to bear the potential of the group to deal with the task on hand. Seeing that the learners of today are the professionals of tomorrow, the facilitator has to respect the learner as a human being who will have an influence on the future of the profession [34].

The facilitator takes on an expert role and is very structured in his/her design, a position to the left end of the continuum will be taken, whereas on the other hand, if the facilitator takes a purely neutral position and just shares his/her observations and allows the group to discover things for themselves using their own processes, the facilitation is positioned at the other end of the continuum. Most facilitation belongs somewhere in the middle of the continuum [33].

To demonstrate, for this educational programme on critical thinking, the facilitator's power differed according to the content and stage of the educational programme. Initially the facilitator played a more dominant role because of the unfamiliar content offered, but afterwards a shift towards shared control took place. Although participants sometimes took the lead in the activities, they could never take over control completely as the facilitator always had to guide them through the activities. During facilitation in a self-directed scenario, learner control also varies on a continuum. It can be assumed that when the facilitator is in control, the learner will not be in such a controlling position [36] [37].

During facilitation of the educational programme, the facilitator (the researcher) endeavoured to maintain certain principles to create a conductive environment for the implementation of the educational programme.

These principles were the following:

- A clear goal was set for each session.

- There was a clear structure in the presentation of the educational programme so that participants always knew what to expect.

- Appropriate recognition was given for all contributions so that participants would have a feeling of belonging.

- A clear idea of the "big picture", in this case execution of critical thinking within the application of nursing practice, was always held up to the participants [30] [38] [39]. Effective facilitation depends on developing a number of strategies, namely the 
management of time, the provision of handouts and the securing of a non-threatening environment. In this educational programme each participant received a properly ring-bound handout which she/he could use and possess during the educational programme. Ground rules for the participation were set and clear instructions were given to the participants [38].

While learning never takes place in a vacuum, the researcher/facilitator tried to build rapport with the whole group during activities. This was very important since some activities demanded the constant presence of the facilitator to achieve the desired outcomes. The interaction between the facilitator and participants is illustrated in Figure 2 .

One strategy where the input and presence of the facilitator were imperative was the utilization of small group discussions.

\section{Small group discussions:}

The utilization of small group discussions in teaching has been emphasized by a number of authors as it facilitates active participation and learning during the presentation of educational programmes or sessions. Therefore, the facilitator opted for the utilization of small group discussions in the presentation of this educational programme. Small group discussions give the participants an opportunity to share their reasoning processes and thereby contribute to the development of critical thinking. Students may learn more from each other than from their facilitator. Small group discussions were therefore an essential focus in the implementation of the educational programme and were employed very successfully during the course of the programme [28] [38] [40].

One of the obstacles that have been identified in the teaching of problem solving is the position where the teacher is the teacher and the participants the learners. This condition can be eliminated by means of small group discussions. However, the role of a facilitator in the utilization of this strategy cannot be ignored.

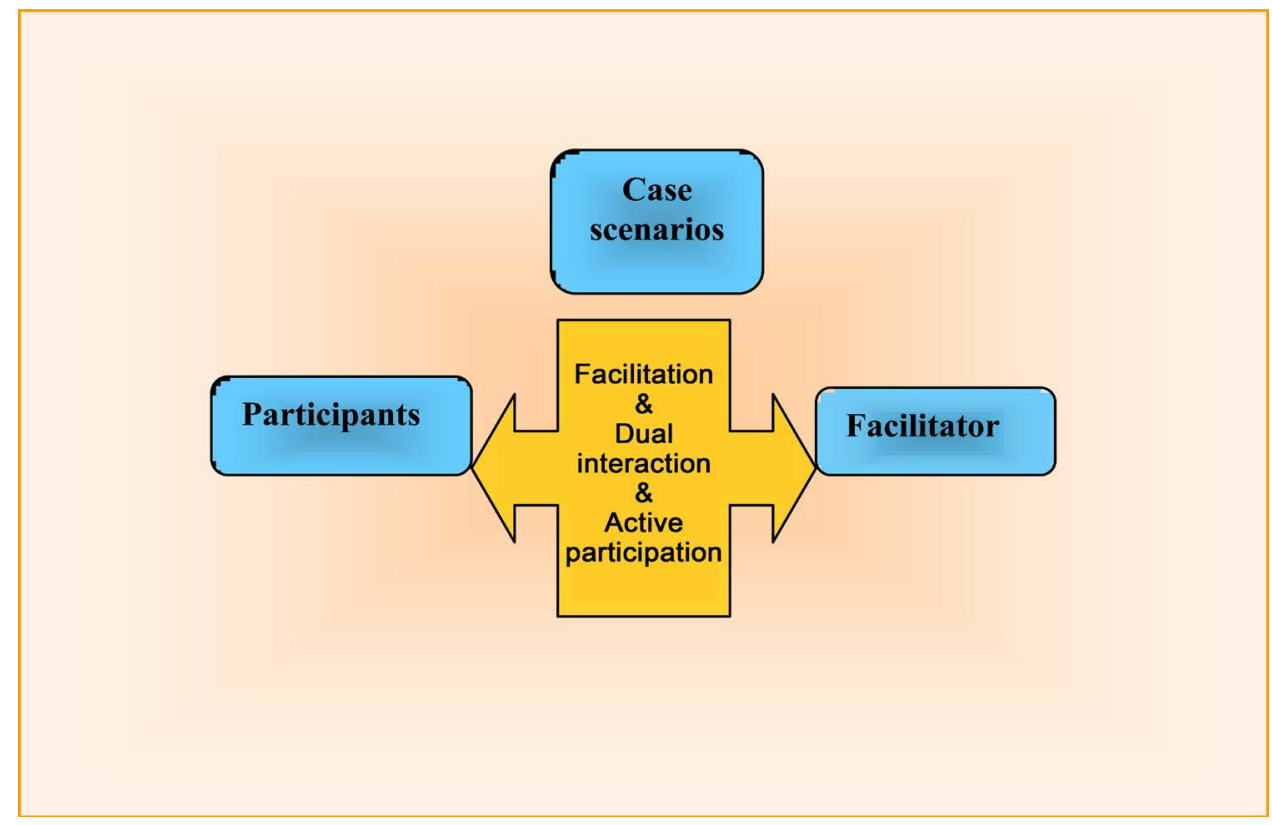

Figure 2. Interaction between the facilitator and participants. 
According to [40], small group discussions can be very frustrating if not well planned but on the other hand very rewarding if well planned. The following principles were kept in mind with the facilitation of the small group discussions for the duration of the educational programme:

- Participants were encouraged to know and respect each other in the group.

- As the facilitator, the researcher kept comments to a minimum and only intervened when necessary.

- Clear goals were set for each session.

- Open-ended questions were asked to limit factual answers but allow creativity.

- Continuous, positive feedback was given during these small group deliberations which served as positive reinforcement [26] [40].

However, interaction was not restricted to small group discussions. Room for dual interaction between participants and the facilitator during the implementation of the educational programme was also allowed. The researcher/facilitator had the vision that, during the implementation of the educational programme, participants would not only learn how to think critically, but that they would motivate each other to grow in learning. Students shared their ideas about specific scenarios with each other and with the whole group. The facilitator made sure that each group of students got a chance at some stage to discuss their view on a specific case or scenario. Not one participant was apathetic, passive or disruptive to the group. All participants participated in the discussions, which became very lively and constructive.

\section{Course material:}

As already indicated, the utilization of case scenarios, based on a real life situation, in the facilitation of critical thinking had been confirmed as a strategy that stimulates critical thinking, retention and recall. A real life situation stimulates the thinking of the participants and enhances creativity since there is no one "right answer" to such a situation. Prerequisites to the setting of these scenarios are that they should be interesting, realistic, and not excessively complex, clearly written and those participants should know what they were expected to do. The presentation of case scenarios which participants could relate to is usually more successful because it encourages classroom or group debates, which in itself enhances critical thinking [41] [42] [43].

[44] argued that involvement in things like case histories generally offers greater learning opportunities for adults than "talking" to learners/students. It is, however, of the first importance that people in the roles of teacher, manager, health care provider or facilitator involve those around them to act with motivation [34] [45].

For this study, the researcher compiled a number of case scenarios from everyday life as well as from nursing practice. The case scenarios facilitated the application of the six main critical thinking concepts that students had to master during the educational programme. These concepts were used as the indicators according to which students' outcomes-based assessment was performed. The outcomes were measured by means of a deductive and descriptive approach to determine whether specific outcomes, set as learning objectives at the beginning of the educational programme, had been achieved 
[35].

\section{Teaching focus of presentation:}

The facilitator (researcher) had a specific focus in mind when presenting the programme. The facilitator moved away from didactic (fact-focused) teaching, where the focus and responsibility is on the teacher, and supported the approach of [46], which used a critical thinking approach to teaching. This approach required a paradigm shift which can refocus the student. In this form of teaching, content "lives" in the form of thinking. According to the author, only the student who "thinks through the content" [46] will truly be able to take possession of the content and make it their own. Teaching about critical thinking involves thinking about thinking, as a result, students who think critically will begin to think at a higher level and improve the clarity, accuracy, relevance, depth, breadth and effectiveness of their thinking.

The focus during the presentation of the educational programme was on conducting an outcomes-based programme which emphasized that the students should accept responsibility for their own learning by exercising self-directed learning. Self-directed learning in an outcomes based educational programme means having clear objectives for students so that they know what they have to strive towards during the educational programme. Setting clear objectives clears up any mystery surrounding what is needed for the success of the educational programme [26] [35] [42] [47].

\section{Conclusions}

This article dealt with the dynamics concerning the implementation of the educational programme to facilitate the development of critical thinking in student nurses. The role of the facilitator during the educational programme was highlighted and the emphasis in the implementation of the educational programme was on active participation. Active participation leads to individual growth, which gives the students confidence, a sense of freedom and identity and a feeling of belonging. Successful facilitation enables the student to benefit fully from the experiences by removing as many obstacles to learning as possible. Without facilitation the students lose direction as they endeavour to learn anything worthwhile from their experience [45] [48] [49] [50]. As [51] has rightfully indicated, "Learning is an ongoing advancing process. Learners build on what they know and can do".

It was concluded that this objective was achieved with the implementation and evaluation of a three-day educational programme on the facilitation of the development of critical thinking within a quasi-experimental design. Students from both the main campus (Windhoek) and the Northern Campus (Oshakati) of the Department of Nursing at the Faculty of Medical and Health Sciences of the University of Namibia were included in the quasi-experiment.

\section{References}

[1] Norton, B. (1998) Selecting Learning Experiences to Achieve Curriculum Outcomes. In: Billings, D.M. and Halstead, J.A., Eds., Teaching in Nursing, Saunders, Tokyo, 151-169. 
[2] Wright, I. (2003) Is That Right? Critical Thinking and the Social World of the Young Learner. Pippin, Toronto.

[3] Youngblood, N. and Beitz, J.M. (2001) Developing Critical Thinking with Active Learning Strategies. Nurse Educator, 26, 39-42. http://dx.doi.org/10.1097/00006223-200101000-00016

[4] Anonymous (1993) Improving Teaching and Learning in Service: Expert Help at Your School or Campus. Critical Thinking, 1, 3-7.

[5] L'Eplattenier, N. (2001) Tracing the Development of Critical Thinking in Baccalaureate Nursing Students. Journal of the New York Nurses Association, 32, 27-32.

[6] Redding, D.A. (2001a) The Development of Critical Thinking among Students in Baccalaureate Nursing Education. Holistic Nursing Practice, 15, 57-64.

http://dx.doi.org/10.1097/00004650-200107000-00009

[7] Alfaro-LeFevre, R. (2002) Applying Nursing Process: Promoting Collaborative Care. 5th Edition, Lippincott, Philadelphia.

[8] Alfaro-Le Fevre, R. (2004b) Critical Thinking and Clinical Judgment. 3rd Edition, Saunders, St. Louis.

[9] Lipe, S.K. and Beasley, S. (2004) Critical Thinking in Nursing: A Cognitive Skills Workshop. Lippincott, Williams \& Wilkins, Philadelphia.

[10] Paul, R. (1990) Critical Thinking. What Every Person Needs to Survive in a Rapidly Changing World. Center for Critical Thinking and Moral Critique, Rohnert Park.

[11] Paul, R. and Nosich, G.M. (1991) A Proposal for National Assessment of Higher Order Thinking at the Community College and University Levels. National Centre for Education Statistics, Washington DC.

[12] McKown, L.K. (1997) Improving Leadership through Better Decision Making: Fostering Critical Thinking. Research Department Air Command and Staff College.

[13] Burns, N. and Grove, S.K. (2005) The Practice of Nursing Research: Conduct, Critique and Utilization. 5th Edition, Elsevier Saunders, Missouri.

[14] De Vos, A. (2002) Intervention Research. In: De Vos, A.S., Ed., Research at Grass Roots: For the Social Sciences and Human Service Professions, 2nd Edition, Van Schaik, Pretoria, 114-126.

[15] Fouche, C.B. and Delport, C.S.L. (2002) In-Depth Review of Literature. In: De Vos, A.S., Ed., Research at Grass Roots. For the Social Sciences and Human Service Professions, 2nd Edition, Van Schaik, Pretoria, 127-136.

[16] Polit, D.E. and Beck, C.T. (2006) Essentials of Nursing Research. 6th Edition, Lippincott Williams \& Wilkins, Philadelphia.

[17] Fouche, C.B. and De Vos, A.S. (2002) Qualitative Research Designs. In: de Vos, A.S., Ed., Research at grass Roots: For the Social Sciences and Human Service Professions, 2nd Edition, Van Schaik, Pretoria, 137-149.

[18] Polit, D.E. and Beck, C.T. (2004) Nursing Research: Principles and Methods. 7th Edition, Lippincott Williams \& Young, Philadelphia.

[19] Brink, H. (2006) Fundamentals of Research Methodology for Health Care Professionals. 2nd Edition, Juta, Cape Town.

[20] Delport, C.S.L. (2002) Quantitative Data Collection Methods. In: De Vos, A.S., Ed., Research at Grass Roots. For the Social Sciences and Human Service Professions, 2nd Edition, Van Schaik, Pretoria, 165-196.

[21] Strydom, H. (2002) The Pilot Study. In: De Vos, A.S., Ed., Research at Grass Roots: For the 
Social Sciences and Human Service Professions, 2nd Edition, Van Schaik, Pretoria, 210-221.

[22] Johnson, D.W., Johnson, R.T. and Stanne, M.B. (2000) Cooperative Learning Methods: A Meta-Analysis.

http://www4.ncsu.edu/unity/lockers/users/f/felder/public/Papers/CLChapter.pdf

[23] Garson, G.D. (2007) Reliability Analysis. PA 765.

https://faculty.chass.ncsu.edu/garson/PA765/statnote.htm

[24] Vockell, E.L. and Asher, J.W. (1995) Educational Research. 2nd Edition, Prentice Hall, Ohio.

[25] Chubinski, S. (1996) Creative Critical Thinking Strategies. Nurse Educator, 21, 23-27. http://dx.doi.org/10.1097/00006223-199611000-00007

[26] Stein, D. (1998) Situated Learning in Adult Education. http://www.ericdigests.org/1998-3/adult-education.html

[27] Cowley, S. (2004) Getting the Buggers to Think. MPG Books, London.

[28] Frazer, M. (1992) Promoting Learning. In: Barnett, R., Ed., Learning to Effect, SRHE \& Open University Press, Buckingham, 55-65.

[29] Conger, M.M. and Mezza, I. (1996) Fostering Critical Thinking in Nursing Students in the Clinical Setting. Nurse Educator, 21, 11-15. http://dx.doi.org/10.1097/00006223-199605000-00005

[30] Banning, M. (2005) Approaches to Teaching: Current Opinions and Related Research. Nurse Education Today, 25, 502-508. http://dx.doi.org/10.1016/j.nedt.2005.03.007

[31] Rylatt, A. and Lohan, K. (1997) Creating Training Miracles. Jossey-Bass, San Francisco.

[32] Johnston, A.K. and Tinning, R.S. (2001) Meeting the Challenge of Problem-Based Learning: Developing the Facilitators. Nurse Education Today, 21, 161-169. http://dx.doi.org/10.1054/nedt.2000.0526

[33] Williams, B. and Walker, L. (2003) Facilitating Perception and Imagination in Generating Change through Reflective Practice Groups. Nurse Education Today, 23, 131-137. http://dx.doi.org/10.1016/S0260-6917(02)00167-3

[34] Ryan, M.R. and Deci, E.L. (2000) Self Determination Theory and the Facilitation of Intrinsic Motivation, Social Development, and Well-Being. American Psychologist, 55, 68-78. http://dx.doi.org/10.1037/0003-066X.55.1.68

[35] Meyer, S.M., Naude, M. and van Niekerk, S. (2004) The Unit Manager: A Comprehensive guide. Heinemann, Sandton.

[36] Cilliers, F. and Terblanche, L. (2000) Facilitation Skills for Nurses. Curationis, 23, 90-97. http://dx.doi.org/10.4102/curationis.v23i4.762

[37] Canton, P. (1996) Professional Development as Transformative Learning. New Perspectives for Teachers of Adults. Jossey-Bass, San Francisco.

[38] Rooth, E. (1995) Lifeskills: A Resource Book for Facilitators. Nolwazi Educational Publishers, Braamfontein.

[39] Myrick, F. and Yonge, O.J. (2001) Creating a Climate for Critical Thinking in the Preceptorship Experience. Nurse Education Today, 21, 461-467. http://dx.doi.org/10.1054/nedt.2001.0593

[40] Cook, J. (2004) Suggestions for Leading Small Group Discussions: A Publication of the Instructional Development Centre. Teaching at Trent, 7, 6.

[41] Rowles, C.J. and Brigham, C. (1998) Strategies to Promote Critical Thinking and Active Learning. In: Billings, D.M. and Halstead, J.A., Eds., Teaching in Nursing, Saunders, Tokyo, 
247-270.

[42] Hale, S. (2005) Case Based Learning: Review of Good Practice. University of Huddersfield. http://giddet.psicol.unam.mx/biblioteca/metod casos/casebasedlearningreview.pdf

[43] Candela, L., Michael, S.R. and Mitchell, S. (2003) Ethical Debates. Enhancing Critical Thinking in Nursing Students. Nurse Educator, 28, 37-39.

http://dx.doi.org/10.1097/00006223-200301000-00013

[44] Knowles, M.S. (1980) The Modern Practice of Adult Education. Follett, Chicago.

[45] CTL (Center for Teaching and Learning) (2005) Speaking of Teaching. Stanford University Newsletter, 15, 1-6. http://ctl.stanford.edu

[46] Cairns, M.A. (1996) Which Should I Teach: Critical Thinking or the Facts? Can I Do Both? http://www.nataec.org/documents/articles/critical thinking.html

[47] Merriam, S.B. and Brockett, R.G. (1997) The Profession and Practice of Adult Education: An Introduction. Jossey-Bass, San Francisco.

[48] Gibbs, G. (1992) Improving the Quality of Student Learning through Course Design. In: Barnett, R., Ed., Learning to Effect, SRHE \& Open University Press, Buckingham, 149-165.

[49] Birchenall, P. (2001) Educational Facilitation: A Developing Role. Nurse Education Today, 21, 249-250. http://dx.doi.org/10.1054/nedt.2001.0597

[50] Anastasi, J. (2004) Re-Entry to Nursing: Student Focus in the Competence Assessment Service Program. Studies in Learning, Evaluation, Innovation and Development, 1, 8-15.

[51] Mentkowski, M. and Associates (2000) Learning That Lasts: Integrating Learning, Development, and Performance in College and Beyond. Jossey Bass, San Francisco.

\section{Submit or recommend next manuscript to OALib Journal and we will provide best} service for you:

- Publication frequency: Monthly

- 9 subject areas of science, technology and medicine

- Fair and rigorous peer-review system

- Fast publication process

- Article promotion in various social networking sites (LinkedIn, Facebook, Twitter, etc.)

- Maximum dissemination of your research work

Submit Your Paper Online: Click Here to Submit

Or Contact service@oalib.com 